\title{
Optimal macronutrient balance
}

\author{
Michael J. Gibney \\ Department of Clinical Medicine, Trinity College Medical School, St James's Hospital, Dublin 8, Republic of Ireland
}

\begin{abstract}
There is at present a justifiable debate as to the optimum level of total dietary fat which will reduce the risk of obesity without an elevation of plasma triacylglycerol or a depression of plasma HDL-cholesterol. Total plasma cholesterol and LDL-cholesterol levels are lowered and risk of fatal myocardial infarction is lowered when either saturated or trans-unsaturated fatty acids are replaced isoenergetically by either monounsaturated or polyunsaturated fatty acids. The triacylglycerol-raising and HDL-lowering effects of low-fat high-carbohydrate diets can be overcome with low intakes of $n-3$ polyunsaturated fatty acids and moderate exercise. Whilst a reduction in dietary fat is being attained in many countries, the reduction is uniform across all fatty acids, leaving dietary fat composition unchanged. The ability of low-fat diets to reduce cholesterol and cause a fall in body weight is not influenced by the carbohydrate ratio starch : sugars in the diet. However, weight-gain susceptibility to high intakes of dietary fat and the plasma cholesterol responsiveness to diet are considerably influenced by common genetic polymorphisms.
\end{abstract}

Dietary fat: Dietary fatty acids: Dietary carbohydrate: Diet and genetics

In considering the optimal balance of macronutrients in the context of a symposium on optimal nutrition, two caveats immediately spring to mind. One is that it is beyond the scope of a brief presentation to address issues which are regularly addressed by committees of experts often over several years. A second is the question of 'optimal for which purpose?'; reproduction, lactation, growth, health, ageing or physical activity. For the purposes of the present paper the focus will be on optimal macronutrient balance for health, and the macronutrients dealt with will be fat (excluding $n-3$ polyunsaturated fatty acids (PUFA)) and carbohydrate, since protein, fibre and $n-3$ PUFA are dealt with elsewhere in the symposium. By way of concluding this introduction, genetic variation in response to dietary intervention will also be considered as a factor impinging on the concept of optimal nutrition.

\section{Dietary fat and dietary carbohydrate level}

Most expert committees (Food and Agriculture Organization/World Health Organization, 1994) which have advised the public on optimal levels of dietary fat have advocated a reduction in the proportion of dietary energy from fat. The benefits are a reduction in plasma levels of both total cholesterol and LDL-cholesterol and a reduction in the risk of developing obesity. There is ample evidence in the literature to show that a reduction in total fat intake lowers blood cholesterol. However, reductions in total fat intake are invariably accompanied by reductions in the intakes of cholesterol-raising saturated fatty acids (SFA). Plasma LDL-cholesterol can readily be reduced without a reduction in fat intake, provided SFA intake is reduced. Thus, if plasma LDL-cholesterol is the chosen end point, dietary fat level is not a critical issue. Indeed, if fatal or nonfatal myocardial infarction is the end point, the data from the Nurses Health Study (n 80082 adult women) would suggest that there is no difference across quintiles of total fat intake (\% energy) in the relative risk of CHD when adjusted for other dietary, lifestyle and clinical variables ( $\mathrm{Hu}$ et al. 1997). Moreover, it is argued that a reduction in total fat intake, accompanied by a rise in carbohydrate intake, leads to a rise in plasma triacylglycerol (TAG) and a fall in plasma HDL-cholesterol which, certainly in women, would increase the risk of CHD (Katan et al. 1997). Consequently it is argued that the level of dietary fat should not be the focus of reduction, but rather the level of cholesterol-raising SFA should be the central public health nutrition message. Two recent studies (Saris et al. 1998; Turley et al. 1998) have failed to demonstrate a rise in plasma TAG and a fall in plasma HDL-cholesterol with low-fat high-carbohydrate diets. Turley et al. (1998) rotated thirty-eight healthy subjects through a standard Western-type diet (36\% energy

\footnotetext{
Abbreviations: Apo, apolipoprotein; MUFA, monounsaturated fatty acids; P diet, high-polyunsaturated fatty acid diet; PUFA, polyunsaturated fatty acids; S diet, high-saturated fatty acid diet; SFA, saturated fatty acids; TAG, triacylglycerols.

Corresponding author: Professor Michael J. Gibney, fax +353 16710672, email mgibney@ ted.ie
} 
from fat, $43 \%$ energy from carbohydrate) and a highcarbohydrate diet (22\% energy from fat, $59 \%$ energy from carbohydrate), with the subjects given advice on how to select a low-fat high-carbohydrate diet. No significant effect on either plasma TAG or HDL-cholesterol was observed. The authors concluded that their study differed from other studies in that the high-carbohydrate diet was freely selected, which compared with studies which observed a rise in plasma TAG where subjects were given either prepared foods, or formula feeds in metabolic wards. That argument seems somewhat simplistic, since many other studies using similar experimental approaches have noted a rise in plasma TAG where subjects self-selected foods according to advice on how to achieve a low-fat highcarbohydrate diet (Roche \& Gibney, 1998). The concept that the method of achieving a low-fat, high-carbohydrate diet determines the plasma TAG is not supported by a second recent study (W Saris, personal communication) where subjects were each assigned to either a low-fat highcarbohydrate diet $(27 \%$ and $53 \%$ energy from fat and carbohydrate respectively, or a control diet (36\% energy from fat, $46 \%$ energy from carbohydrate) and where the experimental low-fat diet was largely achieved by subjects receiving prepared low-fat foods from the investigators. No significant effect on plasma TAG or HDL-cholesterol was noted. Thus, it cannot be stated that in all instances low-fat high-carbohydrate diets will elevate plasma TAG. It may be that the initial level of plasma TAG is of importance. In the study of Turley et al. (1998) and in the CARMEN study (W Saris, personal communication) fasting plasma TAG levels were 1.41 and $1.60 \mathrm{mmol} / \mathrm{l}$ respectively. However, in the case of Roche \& Gibney (1996) and Mensink \& Katan (1987), where low-fat high-carbohydrate diets significantly elevated plasma TAG levels, the fasting plasma TAG levels were much lower $(0.95$ and $0.86 \mathrm{mmol} / 1$ respectively). Clearly, it is a matter of importance in nutrition policy development to clarify the factors which determine plasma TAG responsiveness to low-fat high-carbohydrate diets.

In terms of influence on body weight, there is extensive experimental and epidemiological evidence that high-fat diets predispose to obesity (Gibney, 1995; Prentice \& Poppitt, 1996). However, a counter-argument to this evidence is that whereas obesity levels have increased by $30 \%$ in the USA between 1976 and 1986, total \% energy from fat has actually fallen. These arguments are somewhat incomplete if the issue of physical activity is not considered, since Prentice \& Jebb (1995) have elegantly demonstrated that the rise in obesity in the UK parallels a rise in sedentary lifestyle, as indicated by the long periods spent watching television and videos, and the numbers of cars per household. It may well be that above a certain level of dietary fat, which may indeed be about the level now prevailing in the USA, physical inactivity is the primary cause of weight gain. Those researchers who argue against a role of high-fat diets in the development of obesity have presented data showing that long-term adherence to a low-fat diet leads to weight losses of only $0 \cdot 8-2.6 \mathrm{~kg}$ (Katan et al. 1997). However, small changes in mean population body weight may be associated with a significant shift in extremes of the distribution of weight in an environment with a moderately-high level of dietary fat and low level of physical activity. As to the optimum level of total fat in the diet, further research is needed to explore why in some studies, but not others, a low-fat diet induces elevated plasma TAG and reduced HDL concentrations. If a low-fat diet includes a low level (approximately $1.0 \mathrm{~g} / \mathrm{d}$ ) of $n$-3 long-chain PUFA, then the TAG-raising effects of lowfat high-carbohydrate diets are negated (Roche \& Gibney, 1996). However, unless nutrition policy can successfully raise $n$-3 PUFA levels, it is necessary to continue to debate the advantages and disadvantages of low-fat diets and to continue to research this complex issue.

\section{Genes, dietary fat and obesity}

In addition to diet and physical activity, a third dimension to the debate of lifestyle and body weight is genetics. Saltzman et al. (1997) studied the effects of low-fat and high-fat diets on energy intake and substrate oxidation in a strictlycontrolled study over $9 \mathrm{~d}$ in seven pairs of identical twins. It is important to note that both the low- and high-fat diets were of equal energy density. In the case of three twin pairs there was an increase in energy intake with the high-fat diet over the low-fat diet. In three twin pairs the opposite was seen, and with one twin pair no effect of dietary fat on energy intake was noted. Although this was a study where a small group of identical twins were subject to detailed metabolic investigation, it is supported in the provision of evidence for a genetic susceptibility to overeating on a highfat diet, leading to obesity, by a prospective epidemiological study of 361 Swedish women over 12 years of follow-up (Heitmann et al. 1995). Mean overall BMI gain was just under $1 \mathrm{~kg} / \mathrm{m}^{2}$. However, the subjects were divided into those who were overweight (BMI $29 \mathrm{~kg} / \mathrm{m}^{2}$ ) and those who were normal weight (BMI $22 \mathrm{~kg} / \mathrm{m}^{2}$ ) at baseline, and each of these groups were further subdivided into those with at least one parent overweight and those with no parents overweight. Increasing dietary fat intake had no effect on BMI in any group other than the one overweight at baseline and with at least one parent overweight. Even then, the elevation in BMI over time occurred only at the 90th percentile of fat intake. Thus, there exists some evidence that obesity may occur with moderately-high-fat diets, and this occurrence of obesity may depend on genetic makeup but almost certainly depends on physical activity levels. Genetic factors may not only play a role in determining the risk of developing obesity, but may also determine the risk of obesity-related morbidity. Thus, Uusitupa et al. (1996) examined fasting plasma insulin levels in women with waist circumferences above or below $1.02 \mathrm{~m}$. In each instance the women were identified for their apolipoprotein (Apo) E phenotype. Those women with the $\mathrm{ApoE}_{3,2}$ phenotype showed no effect of waist circumference on fasting insulin. In the case of the $\mathrm{ApoE}_{3,3}$ phenotype, fasting insulin was $33 \%$ higher in women with the higher waist circumference, while in the ApoE $_{4,3+4,4}$ phenotype fasting insulin was doubled with increasing waist size. Clearly, future research will identify further genetic determinants of obesity co-morbidities.

\section{Composition of dietary fat}

As indicated in the preceding section, there is ample evidence to show that a reduction in the level of the SFA 
will reduce LDL-cholesterol, irrespective of dietary fat level. Dietary fatty acid composition is not just relevant to plasma LDL-cholesterol but also to the coagulation system from platelet function to Factor VII activity. Several studies using different approaches have failed to find a role for different dietary fatty acid patterns on different aspects of the coagulation system (Roche \& Gibney, 1997; Temme et al. 1998), while other studies have provided data to suggest that certain aspects of the coagulation pathway are fatty acid-sensitive (Mitropoulos et al. 1994). To try to examine the role of individual dietary fatty acids in each of these spheres of risk of CHD is too complex an issue, since the relative importance of each of these spheres for CHD cannot be readily established. An alternative approach is to examine epidemiological data where fatal or non-fatal myocardial infarction is the outcome. Hu et al. (1997) examined the independent effects of total, SFA, PUFA and monounsaturated fatty acids (MUFA) on the risk of CHD in a prospective (14-year follow-up) study of 80082 women. When all lifestyle, clinical and non-lipid dietary variables were controlled for in a multivariate model the following were noted: if $5 \%$ energy from SFA was replaced with $5 \%$ energy from carbohydrates, CHD risk fell by about $15 \%$; if $5 \%$ energy from SFA was replaced with $5 \%$ energy from MUFA or PUFA, the reductions in CHD risk would be 30 and $45 \%$ respectively. The greatest reduction in CHD risk $(>50 \%)$ was achieved where $2 \%$ energy from transunsaturated fatty acids was replaced with MUFA or PUFA. In effect, the evidence suggests that reducing SFA, and particularly trans-unsaturated fatty acids, by replacement with either MUFA or PUFA while maintaining carbohydrate: fat value constant will provide optimal benefit in terms of CHD.

The two issues of $\%$ energy from fat $v$. fatty acid composition of dietary fats need also to be examined in the context of prevailing patterns of dietary fat intake. Table 1 provides data on the composition of dietary fat in several EU countries at lower and higher levels of dietary fat intake. It is evident that in northern EU countries, the composition of dietary fat remains unchanged, irrespective of the level of dietary total fat. In other words, when populations choose lower-fat diets, they lower their intakes of all categories of fatty acids equally such that fatty acid composition remains unchanged. The same situation is broadly true of southern EU countries. Clearly, the present strategy is tending to favour retention of existing fatty acid patterns, and public health nutrition policy needs to review whether this outcome is a cause for concern.

\section{Genes, dietary fatty acids and plasma cholesterol}

It has long been recognized that some individuals respond better than others to dietary and indeed pharmacological intervention for risk-factor reduction. More recently, the contribution of genetics to this variation in response has become clearer. Cox et al. (1995) rotated sixty-seven healthy subjects through high-fat diets $(38 \%$ energy from fat) which were either high in PUFA (P diet) or high in SFA (S diet). The subjects followed each diet twice in either an SPSP or PSPS cycle. Of the sixty-seven subjects, twentyfive $(37 \%)$ were consistent hyper-responders, twenty-one (31\%) were consistent minimal responders and twenty-one (31\%) were variable responders. Fielding et al. (1995) compared the responses of Caucasians and non-Caucasians to diets high $(600 \mathrm{mg})$ or low $(200 \mathrm{mg})$ in dietary cholesterol, where each of these diets was subdivided into a high $(0.8)$ or low $(0 \cdot 30)$ PUFA:SFA value. At low levels of dietary cholesterol, the dietary PUFA:SFA value made no difference to non-Caucasians in terms of plasma cholesterol. At higher cholesterol levels in the diet, the plasma cholesterol response differed slightly in the non-Caucasians consuming the low PUFA:SFA (increased by $0.28 \mathrm{mmol} / \mathrm{l}$ ) and the high PUFA:SFA (increased by $0.41 \mathrm{mmol} / \mathrm{l}$ ) diets. However, the corresponding values for Caucasians on the high cholesterol intake were increases of 0.47 and $0.78 \mathrm{mmol} / \mathrm{l}$. Both studies indicate within and between ethnic group variation in respect of their response to the effects of dietary fat variation on plasma cholesterol. Moving from ethnic variation to genetic variation, Ordovas et al. (1995) have reviewed the effect of ApoE phenotype on dietary intervention to lower LDL-cholesterol. Four studies showed no effect of $\mathrm{ApoE}_{4}$ phenotype where the only dietary change was in cholesterol level. In contrast $\mathrm{ApoE}_{4}$ phenotype compared with non-ApoE ${ }_{4}$ phenotypes showed significantly

Table 1. The fatty acid composition of dietary fat $(\mathrm{g} / 100 \mathrm{~g})$ at high and low levels of total dietary fat intake in several EU countries

\begin{tabular}{|c|c|c|c|c|c|c|c|c|c|}
\hline Country & Reference & \multicolumn{4}{|c|}{ Low total dietary fat } & \multicolumn{4}{|c|}{ High total dietary fat } \\
\hline \multicolumn{10}{|l|}{ Northern EU } \\
\hline Belgium & De Henauw \& De Backer (1999) & 31 & 43 & 38 & 19 & 52 & 43 & 38 & 19 \\
\hline The Netherlands & Löwik et al. (1999) & 30 & 41 & 39 & 19 & 45 & 40 & 40 & 20 \\
\hline \multicolumn{10}{|c|}{ Southern EU } \\
\hline Greece & Moschandreas \& Kafatos (1999) & 27 & 34 & 51 & 15 & 53 & 30 & 57 & 13 \\
\hline Portugal & Graca (1999) & NA & 32 & 48 & 20 & NA & 36 & 47 & 18 \\
\hline Spain & Serra-Majem et al. (1999) & 33 & 36 & 50 & 14 & 42 & 39 & 50 & 13 \\
\hline
\end{tabular}

NA, not available; SFA, saturated fatty acids; MUFA, monounsaturated fatty acids; PUFA, polyunsaturated fatty acids. 
different LDL changes with diets where the level of fat (ten studies) or the type of fat (two studies) were altered. Pajukanta et al. (1996) studied eighty-seven subjects on a low-fat diet (24\% energy from fat) with a low level of SFA (7 \% energy from fat). Of the subjects $89 \%$ had the ApoB signal peptide (del/del) polymorphism, and this group showed no response in terms of LDL- or HDL-cholesterol to a low-fat low-SFA diet. Approximately $15 \%$ of subjects had the $\mathrm{X}^{+} / \mathrm{X}^{+}$ApoB ( $\mathrm{X}$ bal) polymorphism, and these subjects did not respond in terms of blood lipids (HDL and LDL) to the low-fat low-SFA diet. Humphries et al. (1996) found that the $\mathrm{H}^{-} \mathrm{H}^{-}$(Hind III) polymorphism of lipoprotein lipase (EC 3.1.1.34) led to a $50 \%$ higher response to a highSFA diet than those with the $\mathrm{H}^{+} \mathrm{H}^{+}$allele. Clearly, as our understanding of the genetic determinants of dietary intervention to improve plasma lipid increases, the efficacy of clinical nutrition intervention will improve. However, it is unlikely to influence public health nutrition programmes.

\section{Composition of dietary carbohydrate}

The two main dietary carbohydrates are starch and sucrose. Conventional wisdom held starch to be the nutritionally more favourable of the two carbohydrate sources, but when the two sources are compared in experimental and epidemiological studies, this conventional wisdom is shown to be unjustified. Van Dokkum et al. (1991) studied the effect of low-fat, high PUFA:SFA diets with either 15 or 21 $\%$ energy from sugars and found both to be equally effective in lowering plasma total, LDL- and HDL-cholesterol. More recently, the multi-centre CARMEN study compared lowfat diets where starch: sugar value was varied (W Saris, unpublished results). They found no significant differences between the two diets over a 6-month period in terms of effects on blood lipids or body weight. Both diets were equal in their cholesterol-lowering weight-reducing properties. Several studies have shown that \% energy from dietary fat and dietary sugars are inversely proportional (Gibney, 1990; Bolton-Smith \& Woodward, 1994) and the latter authors have shown clearly that as \% energy from sugar falls and $\%$ energy from fat rises, the incidence of obesity rises. As the relative contributions of fat and sugar vary, the level of starch remains constant, as indeed do levels of micronutrients. Flynn et al. (1996) have used UK dietary data to show that about $80 \%$ energy is provided from staple foods (bread, cereals, rice, potatoes, pasta, meat, poultry, fish, fruit and vegetables) and that these staple foods provide $>95 \%$ of most micronutrient intake. The remaining $20 \%$ energy is provided by pure-fat zero-sugar foods (fats, oils) and by pure-sugar zero-fat foods (sugar, soft-drinks and sugar confectionery). Individuals move along the sugar-fat see-saw according to their taste preferences, without any effect on protein, starch, fibre or micronutrient levels in their diet. Thus, there seems little justification for providing any advice to specifically alter the present sugar: starch balance in the diet.

\section{Conclusion}

The single biggest requirement for improving macronutrient balance is to lower intakes of SFA and trans-unsaturated fatty acids. Whether this reduction should be accompanied by a reduction in fat intake is still a subject for debate. At present there seems little evidence to suggest that the starch : sugar value in Western diets should be altered.

\section{References}

Bolton-Smith C \& Woodward M (1994) Dietary composition and fat to sugar ratios in relation to obesity. International Journal of Obesity 18, 820-828.

Cox C, Mann J, Sutherland W \& Ball M (1995) Individual variation in plasma cholesterol response to dietary saturated fat. British Medical Journal 311, 1260-1264.

De Henauw S \& De Backer G (1999) Nutrient and food intakes in selected subgroups of Belgian adults. British Journal of Nutrition 81, Suppl. 2, S37-S42.

Fielding CJ, Havel RJ, Todd KM, Yeo KE, Schloetter MC, Weinberg V \& Frost PH (1995) Effects of dietary cholesterol and fat saturation on plasma lipoproteins in an ethnically diverse population of healthy young men. Journal of Clinical Investigation 95, 611-618.

Flynn MAT, Sugrue DD, Codd MB \& Gibney MJ (1996) Women's dietary fat and sugar intakes: implications for foodbased dietary guidelines. European Journal of Clinical Nutrition 50, 713-719.

Food and Agriculture Organization/World Health Organization (1994) Food and Oils in Human Nutrition. FAO Food and Nutrition Paper no. 57. Rome: FAO.

Gibney MJ (1990) Dietary guidelines: a critical appraisal. Journal of Human Nutrition and Dietetics 6, 13-22.

Gibney MJ (1995) Epidemiology of obesity in relation to nutrient intake. International Journal of Obesity 19, Suppl. 5, S1-S3.

Graca P (1999) Dietary guidelines and food, nutrient intakes in Portugal. British Journal of Nutrition 81, Suppl. 2, S99-S103.

Heitmann BL, Lissner L, Sorensen TIA \& Bengtsson C (1995) Dietary fat intake and weight gain in women genetically predisposed for obesity. American Journal of Clinical Nutrition 61, 1213-1217.

Hermann-Kunz E \& Thamm M (1999) Dietary recommendations and prevailing food and nutrient intakes in Germany. British Journal of Nutrition 81, Suppl. 2, S61-S69.

Hu FB, Stampfer MJ, Manson JE, Rimm E, Colditz GA, Rosner BA, Hennekens CH \& Willett WC (1997) Dietary fat intake and the risk of coronary heart disease in women. New England Journal of Medicine 337, 1491-1499.

Humphries SE, Talmud PJ, Cox C, Sutherland W \& Mann J (1996) Genetic factors affecting the consistency and magnitude of changes in plasma cholesterol in response to dietary challenge. Quarterly Journal of Medicine 89, 671-680.

Katan MB, Grundy SM \& Willett WC (1997) Beyond low-fat diets. New England Journal of Medicine 337, 563-565.

Lowik MRH, Hulshof KFAM \& Brussaard JH (1999) Patterns of food and nutrient intakes of Dutch adults according to intakes of total fat, saturated fatty acids, dietary fibre and of fruit and vegetables. British Journal of Nutrition 81, Suppl. 2, S91-S98.

Mensink RP \& Katan MB (1987) Effect of monounsaturated fatty acids versus complex carbohydrates on high-density lipoproteins in healthy men and women. Lancet i, 122-125.

Mitropoulos KA, Miller GJ, Martin JC, Reeves BEA \& Cooper J (1994) Dietary fat induces changes in Factor VII coagulant activity through effects on plasma free stearic acid concentration. Arteriosclerosis and Thrombosis 14, 214-222.

Moschandreas J \& Kafatos A (1999) Food and nutrient intakes of Greek (Cretan) adults. Recent data for food-based dietary guidelines in Greece. British Journal of Nutrition 81, Suppl. 2, S71-S76. 
Ordovas JM, Lopez-Miranda J, Mata P, Perez-Jimenez F, Lichtenstein AH \& Schaefer EJ (1995) Gene-diet interactions in determining plasma lipid response to dietary intervention. Atherosclerosis 118, S11-S27.

Pajukanta PE, Valsta LM, Aro A, Pietinen P, Helio T \& Tikkanen MJ (1996) Effects of apolipoprotein B signal peptide (ins/del) and $\mathrm{XbaI}$ polymorphisms on plasma lipid responses to dietary change. Atherosclerosis 122, 1-10.

Prentice AM \& Jebb SA (1995) Obesity in Britain: Gluttony or sloth. British Medical Journal 311, 437-439.

Prentice AM \& Poppitt SD (1996) Importance of energy density and macronutrients in the regulation of energy intake. International Journal of Obesity 20, Suppl. 2, S18-S23.

Roche HM \& Gibney MJ (1996) Postprandial triacylglycerolaemia: the effect of low-fat dietary treatment with and without fish oil supplementation. European Journal of Clinical Nutrition 50, 617-624.

Roche HM \& Gibney MJ (1997) Postprandial coagulation factor VII activity: the effect of monounsaturated fatty acids. British Journal of Nutrition 77, 537-549.

Saltzman E, Dallal GE \& Roberts SB (1997) Effect of high-fat and low-fat diets on voluntary energy intake and substrate oxidation: studies in identical twins consuming diets matched for energy density, fiber and palatability. American Journal of Clinical Nutrition 66, 1332-1339.
Serra-Majem L, Ribas L \& Ramon JM (1999) Compliance with dietary guidelines in the Spanish Population. Results from the Catalan Nutrition Survey. British Journal of Nutrition (In the Press).

Temme EHM, Mensink RP \& Hornstra G (1998) Individual saturated fatty acids and effects on whole blood aggregation in vitro. European Journal of Clinical Nutrition 52, 697-702.

Turley ML, Skeaff CM, Mann JI \& Cox B (1998) The effect of lowfat, high-carbohydrate diet on serum high-density lipoprotein cholesterol and triglyceride. European Journal of Clinical Nutrition 52, 728-733.

Uusitupa MIJ, Karhunen L, Rissanen A, Franssila-Kallunki A, Niskanen L, Kervinen K \& Kesaniemi YA (1996) Apolipoprotein $\mathrm{E}$ phenotype modifies metabolic and haemodynamic abnormalities related to central obesity in women. American Journal of Clinical Nutrition 64, 131-136.

Valsta LM (1999) Food-based dietary guideline for Finland - a staged approach. British Journal of Nutrition 81, Suppl. 2, S49S55.

Van Dokkum W, van der Beek EJ, de Pee S, Schaafsma G, Westra A \& Wedel M (1991) Dutch dietary guidelines: impact on blood lipids, blood pressure, body composition and urinary mineral excretion of Dutch middle aged men. European Journal of Clinical Nutrition 45, 43-439. 
https://doi.org/10.1017/S0029665199000555 Published online by Cambridge University Press 